\title{
Methanolic Extract of Distemonanthus benthamianus (Caesalpiniaceae) Stem Bark Suppresses Ethanol/Indomethacin- Induced Chronic Gastric Injury in Rats
}

\author{
Vanessa Mba Matah Marte, ${ }^{1}$ Gilbert Ateufack ${ }^{D},{ }^{1}$ Marius Mbiantcha ${ }^{D},{ }^{1}$ \\ Albert Donatien Atsamo, ${ }^{2}$ Carine Flore Adjouzem, ${ }^{1}$ Stéphanie Flore Djuichou Nguemnang, \\ Eric Gonzal Tsafack, ${ }^{1}$ William Yousseu Nana, ${ }^{1}$ Yacine Karelle Madjo Kouam, ${ }^{1}$ \\ and Elvira Ngoufack Azanze ${ }^{1}$
}

${ }^{1}$ Laboratory of Animal Physiology and Phytopharmacology, Faculty of Science, University of Dschang, Cameroon

${ }^{2}$ Laboratory of Animal Physiology, Faculty of Science, University of Yaounde I, P.O. Box 812, Yaoundé, Cameroon

Correspondence should be addressed to Gilbert Ateufack; ateufack2000@yahoo.fr

and Marius Mbiantcha; mbiantchamarius@yahoo.fr

Received 15 May 2020; Revised 1 August 2020; Accepted 15 November 2020; Published 28 November 2020

Academic Editor: Roberto Caronna

Copyright (c) 2020 Vanessa Mba Matah Marte et al. This is an open access article distributed under the Creative Commons Attribution License, which permits unrestricted use, distribution, and reproduction in any medium, provided the original work is properly cited.

\begin{abstract}
Distemonanthus benthamianus (Caesalpiniaceae) is a plant from the Cameroon pharmacopoeia very widely used in the treatment of many pathologies among which are gastrointestinal disorders. The main purpose of this study was to assess the healing properties of gastric ulcer from the methanolic extract of Distemonanthus benthamianus and its mechanisms of action. The healing properties of gastric ulcers (chronic ulcer model induced by ethanol and indomethacin) were evaluated in vivo in adult male rats, while the mechanisms of action were evaluated in vitro by anti-inflammatory assay (protein denaturation, cyclooxygenase, and lipoxygenase assays) and immunomodulatory assay (ROS production (using technical chemiluminescence), cytokine (TNF- $\alpha$, IL-1 $\beta$, IL-6) production (using ELISA), proliferation of T cells (using liquid scintillation counter), and cytotoxicity (using MTT assay)). The methanolic extract of Distemonanthus benthamianus inhibited protein denaturation $(75.63 \%)$ and the activities of cyclooxygenase (78.92\%) and 5-lipoxygenase $(81.54 \%)$. The extract also significantly $(p<0.001)$ inhibited intracellular and extracellular ROS production and T cell proliferation and reduced significantly $(p<0.01, p<0.001)$ TNF- $\alpha$, IL-1 $\beta$, IL-6, and PGE2 production. At all doses $(125,250$, and $500 \mathrm{mg} / \mathrm{kg}$ ), the extract significantly reduces the ulceration index and the area of ulceration and significantly increases the mass of gastric mucus. In addition, the extract significantly decreases the level of MDA, significantly increases the activities of catalase and glutathione, and then improves the hematological parameters in sick animals. Histological micrographs show that in the presence of the extract, there is advanced reepithelialization with recovery of the ulcerated epithelium. Thus, the extract of Distemonanthus benthamianus has healing properties against gastric ulcers which are associated with its anti-inflammatory, immunomodulatory, and antioxidant effects.
\end{abstract}

\section{Introduction}

Caesalpiniaceae represent a plant family made up of subtropical and tropical shrubs and trees with more than 150 genera and around 2200 species. The leaves have the characteristics of being stipulated, alternate, pinnate, bipinnate, or simple with a petiole very often enlarged at the base. The flowers of this plant family, zygomorphic and strongly perigynous, appear in spikes, in clusters, or in cymes. Their fruits are generally legumes [1]. Several species of Caesalpinioideae are highly sought after because of their ornamental characteristics. In addition, several of these species produce numerous resins, very precious wood, and above all medicinal substances [2]. Distemonanthus benthamianus ( $D$. benthamianus) is a species 
belonging to the large family of Caesalpiniaceae and which is very widespread in Africa where it is widely used for its many therapeutic virtues.

D. benthamianus, still known as Movingui in Gabon, Barre in Ivory Coast, Bonsamdua in Ghana, Eyen in Cameroon, and Ayan in Nigeria, is one of the largest trees widespread in Africa, with a height of 90 to $125 \mathrm{~m}$ and evergreen. On the ethnopharmacological level, the barks, leaves, and roots of this plant are used to treat many pathologies among which are nervous disorders, constipation, digestive disorders, and dropsy. A decoction of the mixture of leaves and bark is used to treat many bacterial infections [3]. In the western region of Nigeria, the Yaouba people use the stem and roots as a chewing stick for oral hygiene [4]. Several studies have shown that extracts from D. benthamianus are rich in alkaloids, flavonoids, polyphenols, saponins, sterols, tannins, and triterpenes $[3,5]$. The work of Nguelefack et al. [3] has shown that D. benthamianus has antibacterial properties in vitro against Staphylococcus aureus and Streptococcus agalactiae, while the work of Yousseu et al. [5] has shown the antidiarrheal properties of the aqueous and methanolic extracts of this plant. Other work has shown that extracts of $D$. benthamianus have spasmolytic and muscle relaxant properties by blocking voltage-gated calcium channels and by inhibition of muscarinic receptors [6]. In addition, an analysis by HPLC of the methanolic extract of $D$. benthamianus showed the presence of gallic acid, which is known for its numerous pharmacological properties, in particular on pathologies of the gastrointestinal tract [7]. The aqueous and methanolic extracts of this plant considerably reduce the serum levels of proinflammatory cytokines (TNF- $\alpha$ and IL-1 $\beta$ ) and facilitate the reconstitution of tissues in the ileum and the colon mucosa [7]; this could justify a potential anti-inflammatory or healing effect of extracts from this plant.

Peptic ulcer is a more or less serious and frequent injury (stomach and duodenum) resulting from a significant imbalance between the endogenous aggressive factors of the wall and the protective factors [8]. Its incidence is greatly increased by factors such as smoking, Helicobacter pylori, alcohol consumption, the use of nonsteroidal anti-inflammatory drugs (NSAIDs), and stress [9], since these factors promote the development and maintenance of lesions of the gastric mucosa with the consequence of the persistence of ulcers with triggering of an inflammatory process. Consumption of alcohol and/or NSAIDs results in the development of ulceration, erosion of the gastric mucosa, perforation, and bleeding $[10,11]$; these effects are consecutive to the excessive production of gastric acid, proinflammatory cytokines (TNF- $\alpha$ and IL- $1 \beta$ ), and reactive oxygen species (ROS), to the increase in lipid peroxidation, to infiltration of neutrophils, and even to apoptosis [12-14]. The increase in all these factors leads to the development and maintenance of an inflammatory process which is characterized by the increase in the activities of cyclooxygenase-2 (COX-2) and 5-lipoxygenase (5-LOX) and an increase in the denaturation of proteins which represent the aggravating factors of inflammation [15].

Based on the fact that preliminary in vitro studies of this study have shown that the stem bark of the methanolic extract of $D$. benthamianus has the property of significantly inhibiting protein denaturation, the activities of COX and
5-LOX, the production of proinflammatory cytokines (TNF $\alpha$, IL-1 $\beta$, IL6), the production of PGE2, and the production of ROS as well as cell proliferation and in addition, this extract is rich in alkaloids, flavonoids, cardiac glycosides, steroids, triterpenoids, tannins, and saponins [3,5] and has gallic acid [7], we can conclude that this plant may have healing properties of gastric ulcers. The objective of this work was to evaluate the healing properties of the methanolic extract of D. benthamianus on the model of chronic ulcer induced by the ethanol and/or indomethacin.

\section{Materials and Methods}

2.1. Plant Material and Extraction. The sample of D. benthamianus (leaves, barks, and flower) was collected in Souza (Littoral region, Cameroon) in November 2017 and a comparison with specimen no. $45488 \mathrm{HCN}$ was authenticated at the national herbarium in Yaoundé (Cameroon). The bark of this plant was discarded, chopped, dried in the shade, and reduced to powder.

The powder $(300 \mathrm{~g})$ was soaked in 3 liters of methanol for $72 \mathrm{~h}$. After filtration, a Büchi rotary evaporator (R-124) set at $65^{\circ} \mathrm{C}$ was used to concentrate the filtrate under reduced pressure. Twenty-two grams ( $22 \mathrm{~g})$ of methanolic extract (yield $7.3 \%(w / w))$ was obtained.

\subsection{In Vitro Assay}

2.2.1. Reagents, Chemicals, and Equipment. Lymphocyte separation medium, luminol, indomethacin, lucigenin, and Hanks Balanced Salt Solution were obtained from MP Biomedicals Inc., Sigma, and Research Organics; ethanol, ammonium chloride of analytical grades, and dimethyl sulfoxide (DMSO) from Merck Chemicals, Darmstadt, Germany; Zymosan A as phorbol myristate acetate from Fluka; and human monocytic leukemia cells from European Collection of Cell Cultures; trypsin and casein were procured from HiMedia Lab. Ltd, Mumbai. Potassium persulfate, N-(1-naphthyl) ethylenediamine dihydrochloride, glutathione, potassium phosphate buffer, and benzene were obtained from LOBA CHEMIE Pvt. Ltd. Mumbai. RPMI 1640 medium and phytohemagglutinin were from Hi-Media. CFA was purchased from Sigma Chemical Co. (St. Louis, MO, USA), while diclofenac (Olfen-100 SR), all other chemicals and reagents were bought in a locally certified pharmacy.

\subsubsection{Anti-Inflammatory Assay}

(1) Inhibition of Protein Denaturation. The extract or diclofenac sodium $(1 \mathrm{ml})$ at concentrations of $100,200,500$, and $1000 \mu \mathrm{g} / \mathrm{ml}$ was mixed with bovine serum albumin (5\%, $1 \mathrm{ml})$ and then incubated at $27^{\circ} \mathrm{C}(15 \mathrm{~min})$. The negative control had only a solution of distilled water and bovine serum albumin. The tubes were placed in a water bath $\left(70^{\circ} \mathrm{C}\right.$, $10 \mathrm{~min}$ ) to cause denaturation of the proteins. Each tube was left for cooling, and the optical density was read at $660 \mathrm{~nm}$. Each test was carried out in three repetitions [16]. The percentage inhibition was calculated using the following formula: 
\%Inhibition $=\frac{\text { Absorbance of control }- \text { Absorbance of sample }}{\text { Absorbance of control }} \times 100$.

(2) Cyclooxygenase and 5-Lipoxygenase Assay. (1) Preparation of Lymphocyte Culture. A culture of human peripheral lymphocytes (RPMI 1640, 20\% fetal bovine serum, and antibiotics) stimulated by phytohemagglutinin was filtered (cellulose acetate of $0.2 \mu \mathrm{m}$ ); after addition of fresh plasma $\left(1 \times 10^{6}\right.$ cells $\left./ \mathrm{ml}\right)$, it was incubated for $72 \mathrm{~h}$. Then, $1 \mu \mathrm{l}$ of lipopolysaccharides was added to the culture which was then incubated for $24 \mathrm{~h}$. The extract or ibuprofen (100 and $500 \mu \mathrm{g} / \mathrm{ml}$, final concentration) was then added, and a new 24-hour incubation was carried out. The tubes were then centrifuged ( $6000 \mathrm{rpm}, 10 \mathrm{~min}$ ) for isolation, the supernatant was removed, and then, the cell lysis buffer ( $50 \mu \mathrm{l})$ was added, and the tubes were again centrifuged (6000 rpm, $10 \mathrm{~min}$ ); then, the pellet was kept for anti-inflammatory tests [17].

(2) Cyclooxygenase Assay. The arachidonic acid was mixed with glutathione, a tripeptide; Tris- $\mathrm{HCl}$ buffer; and hemoglobin and then incubated $\left(37^{\circ} \mathrm{C}, 20 \mathrm{~min}\right)$. Then, $0.2 \mathrm{ml}$ of TCA $(10 \%, 1 \mathrm{~N} \mathrm{HCl})$ and $0.2 \mathrm{ml}$ of TBA were also added and the contents were passed through a boiling water bath $(20 \mathrm{~min})$. After cooling and centrifuging $(1000 \mathrm{rpm})$ for $3 \mathrm{~min}$, the COX activity was determined in the supernatant by reading the optical density at $632 \mathrm{~nm}$ [17].

(3) 5-Lipoxygenase Assay. Sodium hydroxide (0.5 N) was added to a Tween 20 bubble-free mixture, linoleic acid $(70 \mathrm{mg})$, and deoxygenated water $(4 \mathrm{ml})$ to give a $25 \mathrm{ml}$ solution. This solution $(0.5 \mathrm{ml})$ was distributed into tubes, and nitrogen gas was added to each tube which was closed and kept in the freezer. A quartz bowl $\left(25^{\circ} \mathrm{C}\right)$ with a light path of $1 \mathrm{~cm}$ allowed the reaction to take place. The test tubes contained Tris buffer $(2.75 \mathrm{ml}, \mathrm{pH} 7.4)$, sodium linoleate $(0.2 \mathrm{ml})$, and the enzyme $(50 \mathrm{ml})$. The activity of 5-LOX was determined by reading the optical density at $234 \mathrm{~nm}$ [17].

\subsubsection{Immunomodulatory Essay}

(1) Isolation of Human Polymorphoneutrophils (PMN). Blood $(10 \mathrm{ml})$ freshly drawn from an adult and healthy person was introduced into a heparinized tube; then, the lymphocyte separation medium and Hanks Balanced Salt Solution $\left(\mathrm{HBSS}^{-}\right.$) were added to the tube which was left to stand (about $30 \mathrm{~min}$ ). After good separation of the solution, the supernatant was removed and introduced into tubes each containing $5 \mathrm{ml}$ of lymphocyte separation medium and then centrifuged $(400 \times \mathrm{g}, 20 \mathrm{~min}$, room temperature). The supernatant was then removed, $1 \mathrm{ml}$ of distilled water was added for exactly $1 \mathrm{~min}$, and then, $1 \mathrm{ml}$ of $\mathrm{HBSS}^{-}$was also added. Subsequently, HBSS $^{-}(5 \mathrm{ml})$ was further added to each tube which was then centrifuged at $300 \times \mathrm{g}\left(4^{\circ} \mathrm{C}\right)$ for $10 \mathrm{~min}$. After removing the supernatant, $\mathrm{HBSS}^{-}(1 \mathrm{ml})$ was added again to each tube which was kept in ice. Both cell number and viability were determined by the trypan blue exclusion method [18]. The concentration used for each test was $1 \times 10^{6}$ cells $/ \mathrm{ml}$.
The human blood samples used in this work were received from a donor following the procedure accepted by the Independent Ethics Committee, ICCBS, University of Karachi, No. ICCBS/IEC-008-BC2015/Protocol/1.0. Blood donors have been informed that it is to be used for an experimental study.

(2) Isolation of Mouse Peritoneal Macrophages. Three NMRI (Naval Medical Research Institute) mice weighing an average of $23 \mathrm{~g}$ received fetal bovine serum ( $1 \mathrm{ml}$, i.p.). After $72 \mathrm{~h}$ and sacrifice (cervical dislocation), $10 \mathrm{ml}$ of RPMI (Roswell Park Memorial Institute) medium $10 \%$ was injected into the peritoneum of each animal. 2 min after injection, the RPMI medium was withdrawn using a syringe introduced into the animals' peritoneum. The liquid was transferred to tubes which were centrifuged at $400 \times \mathrm{g}\left(4^{\circ} \mathrm{C}\right)$ for $20 \mathrm{~min}$; then, the supernatant was removed and $5 \mathrm{ml}$ of incomplete RPMI was added again followed by further centrifugation $(300 \times$ $\left.\mathrm{g}, 4^{\circ} \mathrm{C}, 10 \mathrm{~min}\right)$. After removal of the supernatant, incomplete RPMI/HBSS ${ }^{-}$medium $(1 \mathrm{ml})$ was added to each tube. Both cell number and viability were determined by the trypan blue exclusion method $[19,20]$. The same cell concentration as the PMN was used for each test.

(3) Chemiluminescence Assay. The chemiluminescence test was carried out in white 96-well plates according to the modified methods of Mesaik et al. [19] and Mahomoodally et al. [20]. Thus, 3.1 to $100 \mu \mathrm{g} / \mathrm{ml}$ of extract ( $25 \mu \mathrm{l})$ or ibuprofen $(25 \mu \mathrm{l})$ and blood $(25 \mu \mathrm{l}$, diluted $(1: 50))$ or PMN $(25 \mu \mathrm{l})$ or macrophages $(25 \mu \mathrm{l})$ was mixed in different wells. Control wells contained only $\mathrm{HBSS}^{++}(25 \mu \mathrm{l})$, blood $(25 \mu \mathrm{l})$, or PMN $(25 \mu \mathrm{l})$ or macrophages $(25 \mu \mathrm{l})$. After incubation $(20 \mathrm{~min}$, $37^{\circ} \mathrm{C}$ ) of the plate in the thermostated luminometer chamber, the zymosan/PMA mixture $(50 \mu \mathrm{l})$ for the extracellular ROS or the luminol/lucigenin mixture $(50 \mu \mathrm{l})$ for the intracellular ROS was added in the respective wells. The plate was directly introduced into the luminometer, and the results were obtained in relative light units (RLU) [21], and the percentage of inhibition was calculated by the following formula:

$$
\operatorname{Inhibition}(\%)=\frac{\left(\mathrm{RLU}_{\text {control }}-\mathrm{RLU}_{\text {sample }}\right) \times 100 \%}{\mathrm{RLU}_{\text {control }}}
$$

(4) Proinflammatory Cytokine Assay. The peritoneal macrophages of harvested mice were washed twice in PBS, adjusted to $10^{6}$ cells $/ \mathrm{ml}$, and cultured in $\mathrm{CO}_{2}\left(37^{\circ} \mathrm{C}, 24 \mathrm{~h}\right)$, in RPMI, and/or with lipopolysaccharides (LPS; $2 \mu \mathrm{g} / \mathrm{ml}$ ) with or without extract $(2,10$, and $50 \mu \mathrm{g} / \mathrm{ml})$. After $24 \mathrm{~h}$, the mixture was centrifuged ( $2500 \mathrm{rpm}, 20 \mathrm{~min}$ ); then TNF- $\alpha$, IL-6, IL$1 \beta$, and PGE2 were determined in the supernatant using the ELISA kits (ELAB Sciences) and following the manufacturer's instructions [22].

(5) Cell Proliferation Assay. To evaluate the effect of the methanolic extract of $D$. benthamianus on cell proliferation, the 96-well white round-bottom plates were used and the protocol described by Mesaik et al. [19] has been used. The extract $(50 \mu \mathrm{l})$ or prednisolone $(50 \mu \mathrm{l})$ of varying concentrations of 2 , 
10 , and $50 \mu \mathrm{g} / \mathrm{ml}$ was mixed with RPMI (5\%) in the different wells. After adding $50 \mu \mathrm{l}$ of T cells $\left(2 \times 10^{6}\right.$ cells $\left./ \mathrm{ml}\right)$, each well was stimulated by adding $50 \mu \mathrm{l}$ of phytohemagglutinin- $\mathrm{L}$ (PHA-L) $(7.5 \mu \mathrm{g} / \mathrm{ml})$. The cells $(50 \mu \mathrm{l})$ and $150 \mu \mathrm{l}$ of $5 \% \mathrm{RPMI}$ constituted the mixture of the negative control wells while the positive control wells consisted of a mixture of cells $(50 \mu \mathrm{l})$, of PHA $(50 \mu \mathrm{l})$, and of 5\% RPMI (100 $\mu \mathrm{l})$. After incubation (5\% $\mathrm{CO}_{2}, 72 \mathrm{~h}, 37^{\circ} \mathrm{C}$ ) of the plate, $25 \mu \mathrm{l}$ of methyl-3H-thymidine $(0.5 \mu \mathrm{Ci})$ was added to each well and the plate was incubated again for $18 \mathrm{~h}$ and cells were harvested using a fiberglass filter. An IS65000 liquid scintillation counter was used to determine the level of thymidine integrated into the cells. The percentage inhibition was determined using the counts per minute (CPM) of each well according to the following formula:

$$
\text { Inhibition activity }(\%)=\frac{\mathrm{CPM}_{(\text {control group })-\mathrm{CPM}_{\text {(test group) }}}}{\mathrm{CPM}_{(\text {control group })}} \times 100 \text {. }
$$

(6) MTT Cytotoxicity Assay. A cell suspension $\left(100 \mu \mathrm{l}, 6 \times 10^{4}\right.$ cells $/ \mathrm{ml}$ ) introduced into wells of a 96-well plate was incubated $\left(5 \% \mathrm{CO}_{2}, 37^{\circ} \mathrm{C}\right)$ for $24 \mathrm{~h}$; then, the medium was removed and then, 3.1 to $100 \mu \mathrm{g} / \mathrm{ml}$ of extract and the complete DMEM was added to each well to give a final volume of $200 \mu \mathrm{l}$ per well. $100 \mu \mathrm{l}$ of cell and the DMEM constituted the mixture of positive control wells while the negative control wells received an additive of $2 \mu \mathrm{l}$ of Triton X-100 (0.5\%). The plate was then incubated for $48 \mathrm{~h}\left(\mathrm{CO}_{2}, 37^{\circ} \mathrm{C}\right)$, the supernatant was removed, and then, $50 \mu \mathrm{l}$ of MTT $(0.5 \mathrm{mg} / \mathrm{ml})$ was added to each and then followed by a new incubation for $4 \mathrm{~h}$. After aspiration of the MTT, $100 \mu \mathrm{l}$ of DMSO was added; then, the plate was shaken (orbital shaker) for 10 to $15 \mathrm{~min}$, and the absorbance was read at $540 \mathrm{~nm}$ [23]. The percentage of inhibition or decrease in cell viability was obtained by the following formula:

$$
\text { \%Inhibition }=100-\frac{\mathrm{OD}_{\text {test group }}-\mathrm{OD}_{\text {blank }}}{\mathrm{OD}_{\text {control group }}-\mathrm{OD}_{\text {blank }}} \times 100 \text {. }
$$

\subsection{In Vivo Assay}

2.3.1. Chemicals and Drugs. DMSO, ethanol, and indomethacin were obtained from Sigma Chemicals. Sucralfate was purchased from an accredited pharmacy (Martyrs, Bafoussam, Cameroon). All chemicals and reagents used were of analytical grade.

2.3.2. Animals. Male Wistar rats weighing between 150 and $200 \mathrm{~g}$ were used. Under natural conditions, they were raised in the animal house of the Animal Biology Department of Dschang University, Cameroon. The animals were fed a standard diet and were given unlimited water. In order to minimize any nonspecific stress, the rats were acclimated for $48 \mathrm{~h}$ before the experiment. The experimental protocols used in this study have been approved by the laboratory committee (Research Unit in Animal Physiology and Phytopharmacology, Department of Animal Biology, Faculty of Science, University of Dschang, Cameroon), in accordance with standard ethical guidelines for the use and the care of laboratory animals, described in the European Community guidelines; EEC Directive 86/609/EEC of 24 November 1986 [24].

2.3.3. Distribution and Treatment of Animals. Forty-two rats were fasted for $48 \mathrm{~h}$. These animals were divided into 7 groups of 6 rats each: groups 1 and 2 composed of rats which will not receive any treatment, group 3 composed of rats which will receive DMSO 3\%, group 4 which will receive sucralfate $(100 \mathrm{mg} / \mathrm{kg})$, and groups 5,6 , and 7 who will receive the methanolic extract of $D$. benthamianus at the respective doses of 125,250 , and $500 \mathrm{mg} / \mathrm{kg}$.

2.3.4. Induction of Gastric Ulcers. Chronic gastric ulcers were induced using the technique described by Wang et al. [25] with modifications. In the first 5 days, $1 \mathrm{ml}$ of absolute ethanol (70\%) was administered orally to animals (except group 1 rats) for the induction of gastric ulcers. On day 6 after the start of this administration, the animals in group 2 were sacrificed; then, their stomach was opened, and the ulcerated surface and the mass of the mucus were measured to confirm the chronicity of the ulcer.

From day 7, animals in groups 3 to 7 received indomethacin by intraperitoneal injection $(10 \mathrm{mg} / \mathrm{kg}, 1 \mathrm{ml} / 200 \mathrm{~g}$ body weight) for 4 consecutive days; subsequently, these animals received the various oral treatments daily for 10 days.

\subsubsection{Macroscopic Assessment of the Ulcerated Area and} Blood Parameters. At the end of the treatment, $\left(10^{\text {th }}\right.$ day $)$, the animals were sacrificed after anesthesia performed using diazepam/ketamine, the stomach was removed and opened along the greater curvature and washed, and mucosal lesions were noted as described by Adinortey et al. [26]. The ulcerated surface, the mass of mucus, and the index of ulceration were determined. The ulcer index (UI) for each rat was recorded according to the average score for ulcer: 0: normal mucosa; 1: 1-4 small petechiae; $2: 5$ or more petechiae or hemorrhagic streaks up to $4 \mathrm{~mm}$ long; and 3: erosion of more than $5 \mathrm{~mm}$ or confluent hemorrhages. Photographs of the gastric mucosa were taken. The cure rate for ulcers (UH \%) was calculated by the following formula:

$$
\mathrm{UH}(\%)=\frac{\mathrm{UI}_{\text {control }}-\mathrm{UI}_{\text {treated }}}{\mathrm{UI}_{\text {control }}} \times 100 .
$$

After sacrifice, catheterization of the abdominal artery was performed to collect blood in a tube filled with anticoagulant (EDTA) for the analysis of hematological parameters (leukocytes (WBC), lymphocytes, monocytes, neutrophils, eosinophils, and basophils). Then, the stomach was removed and part was removed, ground in a buffer, and centrifuged at $3000 \mathrm{rpm}$ for $15 \mathrm{~min}$ at $4^{\circ} \mathrm{C}$; then, the supernatant of the gastric homogenates was removed to measure the oxidative stress parameters such as cellular glutathione (GSH) according to the method described by Ellman [27], superoxide dismutase (SOD) according to the method described by Misra and Fridovich [28], catalase according to the method described by Sinha [29], and malondialdehyde (MDA) according to the method described by Wilbur et al. [30]. 
2.4. Histological Examinations. The rest of the stomach was kept in $10 \%$ formalin solution, followed by tissue dehydration with alcohol and xylene. Each sample was included in paraffin, sectioned at $5 \mu \mathrm{m}$ on thin slides, stained with hematoxylin/eosin mixture, and finally observed under an optical microscope.

\section{Statistical Analyses}

One-way analysis of variance (ANOVA) was used to analyze the data, followed by a Tukey post hoc test. Statistical significance was acceptable at $p<0.05$, and all data are plotted as mean \pm SEM. The software program R.3.5.0 was used.

\section{Results}

\subsection{In Vitro Assay}

\subsubsection{Anti-Inflammatory Activities}

(1) Effect of Methanolic Extract of D. benthamianus on the Inhibition of Protein Denaturation. Table 1 presents the effect of the methanolic extract of $D$. benthamianus on the denaturation of proteins. It appears from this table that the extract inhibited the denaturation of proteins caused by heat. Indeed, a significant inhibition $(p<0.001)$ of $58.52 \%$, $60.39 \%, 64.18 \%$, and $75.63 \%$ is obtained with the extract at concentrations of $100,200,500$, and $1000 \mu \mathrm{g} / \mathrm{ml}$, while diclofenac produced an inhibition of $74.41 \%, 76.72 \%, 81.48 \%$, and $89.19 \%$ at the same concentrations.

(2) Effect of Methanolic Extract of D. benthamianus Inhibiting the Activity of Cyclooxygenase. The evaluation of the effect of the extract on the activity of cyclooxygenase determines the effect of the extract on the production of prostaglandins (Table 1). It appears from the result obtained that at concentrations of 500 and $1000 \mu \mathrm{g} / \mathrm{ml}$, the methanolic extract of $D$. benthamianus significantly inhibits $(p<0.001)$ the activity of cyclooxygenase by $64.31 \%$ and $78.92 \%$, respectively, while at the same concentrations, ibuprofen inhibits this activity by $93.06 \%$ and $97.51 \%$.

(3) Effect of Methanolic Extract of D. benthamianus on the Inhibition of 5-Lipoxygenase Activity. To study the effect of the extract on the production of leukotrienes, evaluation of the effect of the extract on the activity of 5-lipoxygenase was used. The results show that the methanolic extract of $D$. benthamianus and ibuprofen at the concentration of $1000 \mu \mathrm{g} / \mathrm{ml}$ significantly inhibit $(p<0.001)$ the activity of 5 lipoxygenase with respective inhibition percentages of $81.54 \%$ and $95.65 \%$ (Table 1).

\subsubsection{Immunomodulatory Assay}

(1) Effect of Methanolic Extract of D. benthamianus on the Production of Intracellular and Extracellular ROS. The effect of the methanolic extract of $D$. benthamianus on the production of reactive species of intracellular oxygen stimulated by zymosan and extracellular stimulated by PMA was evaluated (Table 2). For intracellular ROS, the methanolic extract of $D$. benthamianus shows significant inhibitory activity with an $\mathrm{IC}_{50}$ of $9.47 \pm 0.12 \mu \mathrm{g} / \mathrm{ml}$ in the blood; $5.59 \pm 0.03 \mu \mathrm{g} / \mathrm{ml}$ by PMN, and $6.05 \pm 0.025 \mu \mathrm{g} / \mathrm{ml}$ by macrophages. Concerning extracellular ROS, the methanolic extract of $D$. benthamianus inhibits their production with $\mathrm{IC}_{50}$ of $8.9 \pm 0.0921 \mu \mathrm{g} / \mathrm{ml}$; $4.40 \pm 0.10 \mu \mathrm{g} / \mathrm{ml}$; and $5.29 \pm 0.37 \mu \mathrm{g} / \mathrm{ml}$, respectively, in the blood, by PMN, and by macrophages.

(2) Effect of Methanolic Extract of D. benthamianus on Cell Proliferation. The extract was tested for its ability to inhibit cell proliferation at concentrations of 2,10 , and $50 \mu \mathrm{g} / \mathrm{ml}$. After stimulation with phytohemagglutinin-L, the methanolic extract of $D$. benthamianus showed a significant antiproliferative property. Table 1 shows that the extract has antiproliferative activity with an $\mathrm{IC}_{50}$ of $3.01 \pm 0.42 \mu \mathrm{g} / \mathrm{ml}$. Prednisolone used as a reference product inhibited cell proliferation with an $\mathrm{IC}_{50}$ lower than $3.10 \mu \mathrm{g} / \mathrm{ml}$.

(3) Effect of Methanolic Extract of D. benthamianus on 3T3 Cells. Concerning the effect of the extract on the viability of 3T3 cells, the results showed that the methanolic extract of D. benthamianus is nontoxic with an $\mathrm{IC}_{50}$ of $32.01 \pm 0.87$ $\mu \mathrm{g} / \mathrm{ml}$ compared to cycloheximide, a cytotoxic reference drug with an $\mathrm{IC}_{50}$ of $0.10 \pm 0.13 \mu \mathrm{g} / \mathrm{ml}$ (Table 1 ).

(4) Effect of Methanolic Extract of D. benthamianus on the Production of Cytokines and PGE2. The effect of the methanolic extract of $D$. benthamianus on the production of TNF- $\alpha$, IL- $1 \beta$, IL- 6 , and PGE2 by macrophages activated by LPS was evaluated (Figure 1). It was noted that at the concentration of $2 \mu \mathrm{g} / \mathrm{ml}$, the methanolic extract of $D$. benthamianus had no significant effect $(p>0.05)$ on the production of TNF- $\alpha$, IL-1 $\beta$, IL- 6 , and PGE2. At the concentration of $10 \mu \mathrm{g} / \mathrm{ml}$, the extract significantly inhibited the production of IL-1 $\beta \quad(p<0.05)$, TNF- $\alpha \quad(p<0.05)$, and PGE2 $(p<0.01)$. At the concentration of $50 \mu \mathrm{g} / \mathrm{ml}$, the extract significantly inhibited the production of TNF- $\alpha$ $(p<0.001)$, IL-1 $\beta(p<0.001)$, IL-6 $(p<0.01)$, and PGE2 $(p<0.001)$.

\subsection{In Vivo Assay}

4.2.1. Effect of Methanolic Extract of D. benthamianus on Chronic Ulcers. Five days after induction of gastric ulcers with ethanol, the animals had an index ulcer of 2.74. Four days after administration of indomethacin and without treatment, the index increases from $2.74 \pm 0.02$ to $3.00 \pm$ 0.03 . Treatment with methanolic extract of $D$. benthamianus produced a significant reduction $(p<0.001)$ in gastric lesions, with index values of $1.00 \pm 0.00 ; 0.17 \pm 0.16$, and 0.00 , corresponding to a healing percentage of $99.90 \%$, $99.97 \%$, and $100 \%$ in animals given 125,250 , and $500 \mathrm{mg} / \mathrm{kg}$, respectively. An increase in mucus secretion of $83.17 \pm 1.28$ $\mathrm{mg}(125 \mathrm{mg} / \mathrm{kg}), 135.50 \pm 4.26 \mathrm{mg}(250 \mathrm{mg} / \mathrm{kg})$, and 173.17 $\pm 3.56 \mathrm{mg}(500 \mathrm{mg} / \mathrm{kg})$ was also recorded in rats treated compared to the neutral control group $(70.50 \pm 4.24 \mathrm{mg})$, negative control $1(48.50 \pm 1.86 \mathrm{mg})$, and negative control 2 $(32.00 \pm 2.29 \mathrm{mg})$. The extract showed a higher activity than that developed by sucralfate $(100 \mathrm{mg} / \mathrm{kg} ;$ p.o. $)$, which showed 
TABLE 1: Effect of methanolic extract of D. benthamianus stem bark on protein denaturation, cyclooxygenase, and 5-lipoxygenase inhibition.

\begin{tabular}{|c|c|c|c|c|c|c|c|}
\hline \multirow{2}{*}{ Treatment } & \multirow{2}{*}{ Dose $(\mu \mathrm{g} / \mathrm{ml})$} & \multicolumn{3}{|c|}{ Activity } & \multicolumn{3}{|c|}{ Inhibition (\%) } \\
\hline & & Protein denaturation & COX & 5-LOX & Protein denaturation & $\mathrm{COX}$ & 5-LOX \\
\hline Control & - & $0.518 \pm 0.004$ & - & - & - & - & - \\
\hline \multirow{4}{*}{ Diclofenac } & 100 & $0.133 \pm 0.002^{c}$ & - & - & 74.41 & - & - \\
\hline & 200 & $0.121 \pm 0.002^{\mathrm{c}}$ & - & - & 76.72 & - & - \\
\hline & 500 & $0.133 \pm 0.002^{\mathrm{c}}$ & - & - & 81.48 & - & - \\
\hline & 1000 & $0.056 \pm 0.001^{\mathrm{c}}$ & - & - & 89.19 & - & - \\
\hline \multirow{4}{*}{ Ibuprofen } & 100 & - & $0.11 \pm 0.006$ & $0.232 \pm 0.022$ & - & 83.51 & 83.16 \\
\hline & 200 & - & $0.018 \pm 0.001^{c}$ & $0.038 \pm 0.001^{\mathrm{c}}$ & - & 88.79 & 87.41 \\
\hline & 500 & - & $0.011 \pm 0.44^{\mathrm{c}}$ & $0.029 \pm 0.005^{\mathrm{c}}$ & - & 93.06 & 91.36 \\
\hline & 1000 & - & $0.007 \pm 0.001^{\mathrm{c}}$ & $0.021 \pm 0.006^{\mathrm{c}}$ & - & 97.51 & 95.65 \\
\hline \multirow{4}{*}{ Methanolic extract } & 100 & $0.215 \pm 0.003^{c}$ & $0.003 \pm 0.002$ & $0.010 \pm 0.001^{\mathrm{c}}$ & 58.52 & 40.98 & 43.86 \\
\hline & 200 & $0.205 \pm 0.002^{c}$ & $0.045 \pm 0.001^{\mathrm{c}}$ & $0.080 \pm 0.005^{\mathrm{c}}$ & 60.39 & 56.15 & 59.42 \\
\hline & 500 & $0.186 \pm 0.002^{c}$ & $0.036 \pm 0.003^{c}$ & $0.060 \pm 0.004^{c}$ & 64.18 & 64.31 & 67.47 \\
\hline & 1000 & $0.126 \pm 0.006^{\mathrm{c}}$ & $0.021 \pm 0.001^{\mathrm{c}}$ & $0.040 \pm 0.003^{\mathrm{c}}$ & 75.63 & 78.92 & 81.54 \\
\hline
\end{tabular}

Each value represents the mean \pm SEM; ${ }^{c} p<0.001$ : significant difference compared to the control group. The percentage values were obtained using various concentrations of test compounds, and readings are presented as mean of triplicates. COX: cyclooxygenase; LOX: 5-lipoxygenase.

TABLE 2: $\mathrm{IC}_{50}$ value of methanolic extract of $D$. benthamianus stem bark on ROS production evaluated by zymosan/PMA-amplified chemiluminescence, on T-cell proliferation and Cytotoxicity.

\begin{tabular}{|c|c|c|c|c|c|c|c|c|}
\hline \multirow{3}{*}{ Treatment } & \multicolumn{6}{|c|}{ Intracellular and extracellular ROS } & \multirow{3}{*}{$\begin{array}{l}\text { T cell proliferation } \\
\left(\mathrm{IC}_{50}(\mu \mathrm{g} / \mathrm{ml})\right)\end{array}$} & \multirow{3}{*}{$\begin{array}{c}\text { Cytotoxicity } \\
\left(\mathrm{CI}_{50}(\mu \mathrm{g} / \mathrm{ml})\right)\end{array}$} \\
\hline & \multicolumn{3}{|c|}{ Luminol/zymosan $\left(\mathrm{IC}_{50}(\mu \mathrm{g} / \mathrm{ml})\right)$} & \multicolumn{3}{|c|}{ PAM/lucigenin $\left(\mathrm{IC}_{50}(\mu \mathrm{g} / \mathrm{ml})\right)$} & & \\
\hline & WB & PMNs & MQ & WB & PMNs & MQ & & \\
\hline $\begin{array}{l}\text { Methanolic } \\
\text { extract }\end{array}$ & $9.47 \pm 0.12$ & $5.59 \pm 0,03$ & $6.05 \pm 0.025$ & $8.91 \pm 0.092$ & $4.40 \pm 010$ & $5.29 \pm 0.37$ & $3.01 \pm 0.42$ & $32.01 \pm 0.87$ \\
\hline Ibuprofen & $15.81 \pm 0.22$ & $15.20 \pm 0.64$ & $15.69 \pm 1.45$ & $17.83 \pm 0.16$ & $15.55 \pm 0.54$ & $16.57 \pm 0.54$ & - & - \\
\hline Prednisolone & - & - & - & - & - & - & $<3.10$ & - \\
\hline Cycloheximide & - & - & - & - & - & - & - & $0.10 \pm 0.13$ \\
\hline
\end{tabular}

The $\mathrm{IC}_{50}$ (median inhibitory concentration) values were obtained using various concentrations of test compounds, and readings are presented as mean \pm standard deviation of triplicates. ROS: reactive oxygen species; WB: whole blood; PMNs: polymorphonuclear leukocytes; MQ: mice peritoneal macrophages.

a healing of $36.22 \%$, an ulcer index of $2.50 \pm 0.01$, and a weight mucus equal to $80.00 \pm 1.69 \mathrm{mg}$ (Table 3 ).

4.2.2. Effect of Methanolic Extract of D. benthamianus on the Macroscopic of the Stomach. Oral administration of ethanol has resulted in gastric damage to the glandular part of the stomach (Figure 2). It appears from this figure that in normal rats, no lesion of the stomach wall is observed (Figure 2(a)). In the negative control 1 rats (Figure 2(b)) as in those of the negative control 2 (Figure 2(c)), inflammatory lesions were observed corresponding to the respective ulceration areas of $12.33 \%$ and $18.37 \%$. Furthermore, the stomachs of animals treated with different doses of the methanolic extract of $D$. benthamianus show a significant reduction in inflammatory lesions corresponding to the ulcer surfaces of $0.02 \%$ (125 mg/kg, Figure 2(e)), 0.01\% (250 mg/kg, Figure 2(f)), and $0.00 \%(500 \mathrm{mg} / \mathrm{kg}$, Figure $2(\mathrm{~g}))$.

4.2.3. Effect of the Methanolic Extract of D. benthamianus on Some Hematological Parameters. Table 4 shows the effect of the extract on some immune cells 10 days after the adminis- tration of ethanol. It appears that the levels of white blood cells, monocytes, neutrophils, and eosinophils increase while the lymphocyte level decreases in animals of negative control groups 1 and 2 compared to the neutral control group. The treatment of rats with the different doses of methanolic extract of $D$. benthamianus leads to an improvement in the hematological parameters evaluated with a reduction in the levels of white blood cells, monocytes, neutrophils, and eosinophils and an increase in the lymphocyte level compared to animals from negative control groups 1 and 2 .

4.2.4. Effect of the Methanolic Extract of D. benthamianus on Some Tissue Parameters of Oxidative Stress. Some tissue parameters of oxidative stress were evaluated at the end of treatment with the different doses of the methanolic extract of $D$. benthamianus, and the results are presented in Table 5. It follows that the MDA level increases while the activities of catalase, SOD, and GSH decreased in rats in negative control groups 1 and 2 compared to animals in neutral control group. Treatment with methanolic extract of $D$. benthamianus and at all doses leads to a significant decrease 


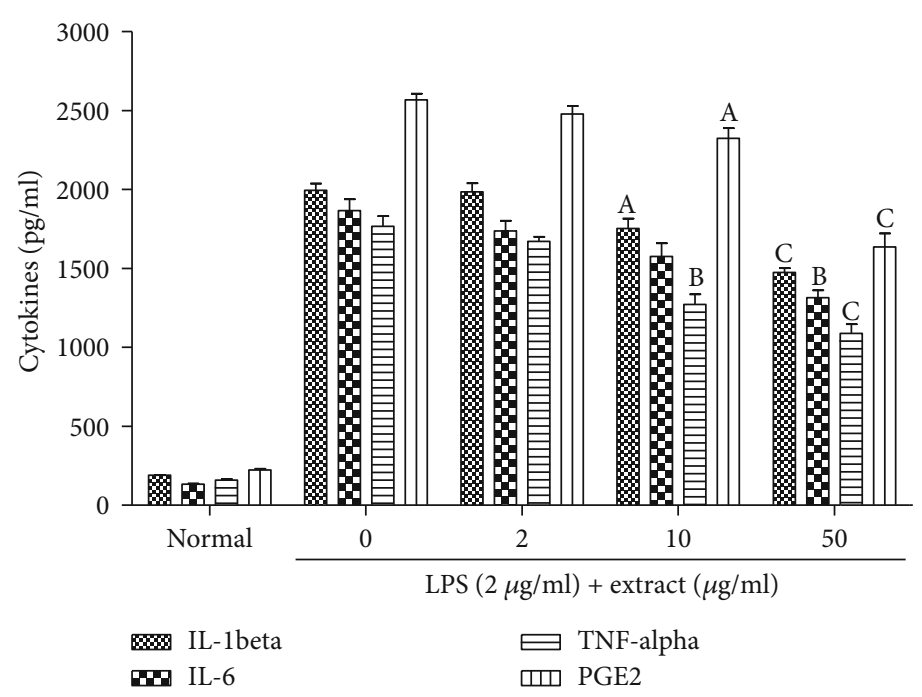

FIGURE 1: Effect of methanolic extract of D. benthamianus on proinflammatory cytokine production stimulated by LPS (lipopolysaccharides). Each value represents the mean \pm SEM; ${ }^{a} p<0.05,{ }^{b} p<0.01$, and ${ }^{c} p<0.001$ : significant difference compared to the normal group. The percentage values were obtained using various concentrations of test compounds, and readings are presented as mean of triplicates. IL: interleukin; TNF: tumor necrosis factor; PGE2: prostaglandin E2.

TABle 3: Effect of methanolic extract of $D$. benthamianus stem bark on ethanol-induced gastric lesions in rats.

\begin{tabular}{lccccc}
\hline Treatment & Dose $(\mathrm{mg} / \mathrm{kg})$ & UI & \%US & \% healing & Mucus weight (mg) \\
\hline Neutral & $/$ & 0.00 & 0.00 & $/$ & $70.50 \pm 4.24$ \\
Control 1 & $/$ & $2.74 \pm 0.02$ & 12.33 & $/$ & $48.50 \pm 1.86$ \\
Control 2 & $/$ & $3.00 \pm 0.03$ & 18.37 & $/$ & $32.00 \pm 2.29$ \\
Sucralfate & 100 & $2.50 \pm 0.01$ & 8.04 & 36.22 & $80.00 \pm 1.69^{\mathrm{c \gamma}}$ \\
& 125 & $1.00 \pm 0.00^{\mathrm{c \gamma}}$ & 0.02 & 99.90 & $83.17 \pm 1.28^{\mathrm{c \gamma}}$ \\
Methanolic extract & 250 & $0.17 \pm 0.16^{\mathrm{c \gamma}}$ & 0.01 & 99.97 & $135.50 \pm 4.26^{\mathrm{c \gamma}}$ \\
& 500 & $0.00 \pm 0.00^{\mathrm{c \gamma}}$ & 0.00 & 100 & $173.17 \pm 3.56^{\mathrm{c \gamma}}$ \\
\hline
\end{tabular}

Each value represents the mean \pm standard error of the mean of 6 animals and analyses by one-way ANOVA followed by Tukey post hoc test; ${ }^{c} p<0.001$ : significant when compared to negative control 1 (ulcerated rats killed 5-day postethanol administration); ${ }^{x} p<0.001$ : significant when compared to negative control 2 (received indomethacin for 4 days $+3 \%$ DMSO for 10 days). UI: ulcer index; US: ulcerated surface.

in the level of MDA, then a significant increase in the activities of catalase, SOD, and GSH compared to animals of negative control groups 1 and 2.

\subsubsection{Effect of Methanolic Extract of D. benthamianus on the} Histology of the Stomach Wall. The stomach of rats which have not undergone ethanol induction of gastric ulcer shows a healthy gastric wall composed from the top to the bottom of the mucous membrane, the muscular mucosa, and the serosa (Figure 3(a)). The stomach of animals subjected to gastric ulcer induction without having received any treatment (Figures 3(b) and 3(c)) climbs a gastric wall with a lesion of the mucous layer (represented by the black arrow) and edemas (represented by the blue arrow). In animals treated with different doses of the methanolic extract of $D$. benthamianus, the stomachs show almost complete healing with significant reepithelialization and no edema (Figure 3(e)). Animals treated with sucralfate showed an incomplete but persistent process of reepithelialization of the ulcerated area (Figure 3(d)).

\section{Discussion}

In the present study, the results show that the methanolic extract of $D$. benthamianus has healing properties for chronic gastric ulcers induced by ethanol and/or indomethacin and via the anti-inflammatory and immunomodulatory mechanisms. Previous studies within the same project showed that the methanolic extract of $D$. benthamianus developed cytoprotective and antisecretory properties against acute ulcers in rats (published work). Additionally, the plant barks are widely used by Cameroonian populations as antiulcerative and on various gastrointestinal lesions of the mucous membranes. In the present study, we evaluated the healing effect of this plant, using an in vivo rat model of chronic gastric lesions induced by ethanol and indomethacin. Further, the mechanisms underlying this effect were evaluated using in vitro assays on the inhibition of protein denaturation, of COX and 5-LOX activities, of ROS production, of proinflammatory cytokines (TNF- $\alpha$, IL-1 $\beta$, IL-6) production, and of PGE2 and cell proliferation production. Our work has shown 


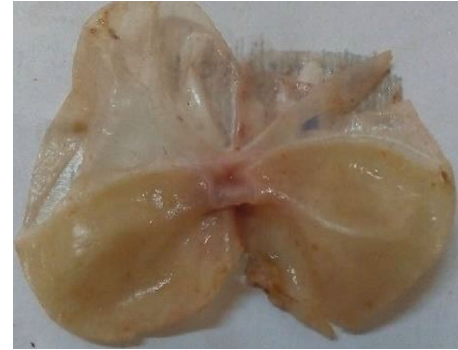

(a)

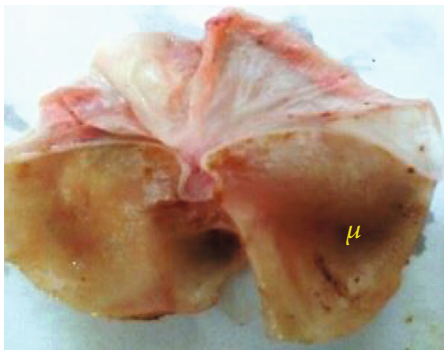

(c)

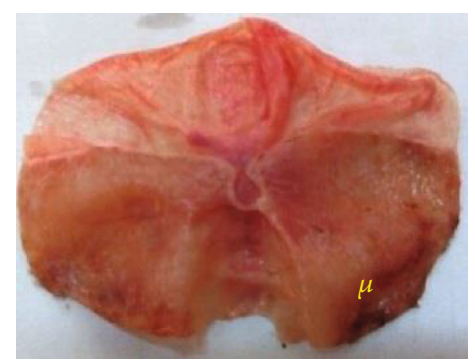

(b)

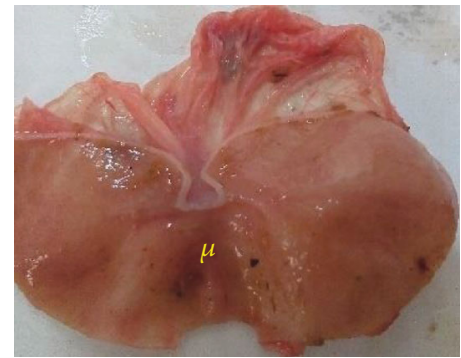

(d)

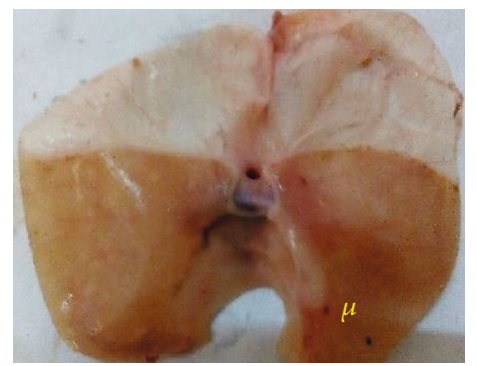

(e)

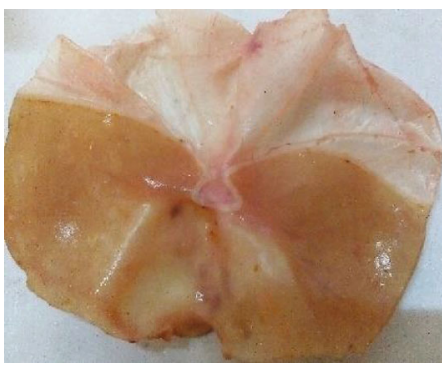

(f)

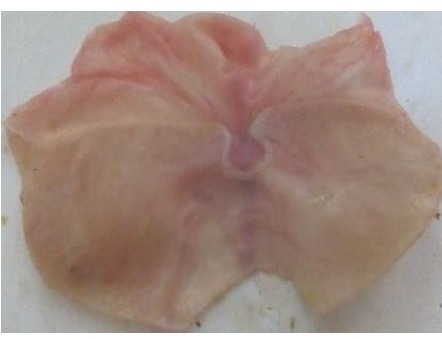

(g)

Figure 2: Macroscopic appearance of the gastric mucosa of the rats: (a) normal group: no lesions are observed; (b) ulcerated rats killed 5 days postethanol administration: severe lesions are seen in the gastric mucosa; (c) ulcerated rats (given indomethacin for 4 days + DMSO3\% for 10 days): lesions are seen in the gastric mucosa with inflammation; (d) sucralfate $(100 \mathrm{mg} / \mathrm{kg})$ : lesions in the gastric mucosa are less than those observed in negative control groups; (e) (125 mg/kg): less lesions; (f) $(250 \mathrm{mg} / \mathrm{kg})$; (g) (500 mg/kg): no lesions are observed; u: ulcer.

TABLE 4: Influence of the methanolic extract of $D$. benthamianus stem bark on some hematological parameters in ethanol-induced gastric lesions in rats.

\begin{tabular}{lcccccc}
\hline Treatment & Dose $(\mathrm{mg} / \mathrm{kg})$ & TWBC $\left(10^{9} / \mathrm{l}\right)$ & Lymphocyte $\left(10^{9} / \mathrm{l}\right)$ & Monocytes $\left(10^{9} / \mathrm{l}\right)$ & Neutrophil $\left(10^{9} / \mathrm{l}\right)$ & Eosinophil $\left(10^{9} / \mathrm{l}\right)$ \\
\hline Neutral & $/$ & $18.00 \pm 0.87$ & $11.14 \pm 0.60$ & $1.12 \pm 0.09$ & $4.44 \pm 0.27$ & $1.30 \pm 0.08$ \\
Control 1 & $/$ & $23.15 \pm 1.17$ & $8.37 \pm 0.31$ & $2.22 \pm 0.27$ & $9.67 \pm 0.41$ & $3.02 \pm 0.17$ \\
Control 2 & $/$ & $20.17 \pm 0.97$ & $8.23 \pm 0.28$ & $2.13 \pm 0.28$ & $8.13 \pm 0.55$ & $3.83 \pm 0.24$ \\
Sucralfate & 100 & $16.50 \pm 0.36^{\mathrm{c \alpha}}$ & $7.93 \pm 0.21$ & $1.17 \pm 0.11^{\mathrm{b} \beta}$ & $6.80 \pm 0.38^{\mathrm{c}}$ & $1.57 \pm 0.08^{\alpha}$ \\
& 125 & $19.40 \pm 0.96^{\mathrm{a}}$ & $10.60 \pm 0.06^{\mathrm{b} \beta}$ & $1.07 \pm 0.06^{\mathrm{b} \beta}$ & $4.03 \pm 0.18^{\mathrm{c \gamma}}$ & $2.97 \pm 0.13$ \\
Methanolic extract & 250 & $17.92 \pm 0.62^{\mathrm{b}}$ & $8.87 \pm 0.39$ & $1.68 \pm 0.21$ & $5.73 \pm 0.29^{\mathrm{cy}}$ & $2.78 \pm 1.22$ \\
& 500 & $18.78 \pm 0.47^{\mathrm{a}}$ & $12.16 \pm 0.50^{\mathrm{c \gamma}}$ & $1.46 \pm 0.06$ & $4.78 \pm 0.09^{\mathrm{cy}}$ & $1.44 \pm 0.13^{\alpha}$ \\
\hline
\end{tabular}

Each value represents the mean \pm standard error of the mean of 6 animals and analyses by one-way ANOVA followed by Tukey post hoc test; ${ }^{a} p<0.05$; ${ }^{c} p<0.001$ : significant when compared to negative control 1 (ulcerated rats killed 5 -day postethanol administration); ${ }^{\alpha} p<0.05$, ${ }^{\mathrm{x}} p<0.001$ : significant when compared to negative control 2 (received indomethacin for 4 days $+3 \%$ DMSO for 10 days); TWBC: total white blood cells.

that the methanolic extract of $D$. benthamianus in vivo considerably reduces gastric lesions with a significant reduction in the ulceration index and a total recovery observed at a dose of $500 \mathrm{mg} / \mathrm{kg}$, then in vitro inhibits significantly the denaturation of proteins, the activities of COX and 5-LOX, and the production of intracellular and extracellular ROS, proinflammatory cytokines, and PGE2 and also inhibits cell proliferation, exhibiting very low cytotoxicity. 
TABLE 5: Effect of methanolic extract of D. benthamianus stem bark on some parameters of oxidative stress in ethanol-induced gastric lesions in rats.

\begin{tabular}{lccccc}
\hline Treatment & Dose $(\mathrm{mgkg})$ & MDA $(\mu \mathrm{mol} / \mathrm{g}$ of organ $)$ & CAT $(\mathrm{U} / \mathrm{g}$ of organ $)$ & GSH $(\mathrm{U} / \mathrm{g}$ of organ $)$ & SOD $(\mathrm{U} / \mathrm{g}$ of organ $)$ \\
\hline Neutral & $/$ & $2.07 \pm 0.19$ & $80.17 \pm 0.02$ & $7.14 \pm 0.44$ & $0.32 \pm 0.02$ \\
Control 1 & $/$ & $5.16 \pm 0.02$ & $34.21 \pm 0.73$ & $4.22 \pm 0.08$ & $0.27 \pm 0.01$ \\
Control 2 & $/$ & $5.10 \pm 0.32$ & $38.48 \pm 0.33$ & $4.96 \pm 0.27$ & $0.28 \pm 0.01$ \\
Sucralfate & 100 & $1.10 \pm 0.00^{\mathrm{c \gamma}}$ & $53.49 \pm 4.00$ & $3.39 \pm 0.03$ & $0.29 \pm 0.01$ \\
& 125 & $1.29 \pm 0.12^{\mathrm{c \gamma}}$ & $66.31 \pm 7.15^{\mathrm{c \gamma}}$ & $6.07 \pm 0.37^{\mathrm{c \gamma}}$ & $0.22 \pm 0.02$ \\
Methanolic extract & 250 & $1.38 \pm 0.08^{\mathrm{c \gamma}}$ & $54.10 \pm 2.13^{\mathrm{c \gamma}}$ & $7.09 \pm 0.42^{\mathrm{c \gamma}}$ & $0.25 \pm 0.01$ \\
& 500 & $1.32 \pm 0.03^{\mathrm{c \gamma}}$ & $47.87 \pm 1.22^{\mathrm{c \gamma}}$ & $6.37 \pm 0.32^{\mathrm{c \gamma}}$ & $0.24 \pm 0.01$ \\
\hline
\end{tabular}

Each value represents the mean \pm standard error of the mean of 6 animals and analyses by one-way ANOVA followed by Tukey post hoc test; ${ }^{c} p<0.001$ : significant when compared to negative control 1 (ulcerated rats killed 5-day postethanol administration); ${ }^{x} p<0.001$ : significant when compared to negative control 2 (received indomethacin for 4 days + 3\% DMSO for 10 days); MDA: malondialdehyde, CAT: catalase; GSH: glutathione; SOD: superoxide dismutase.

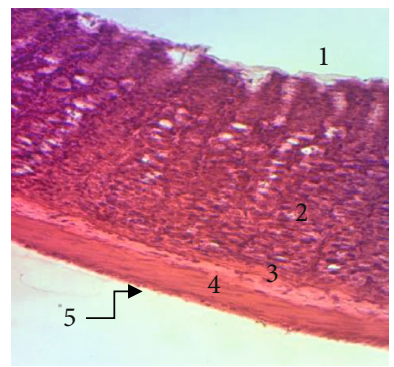

(a)

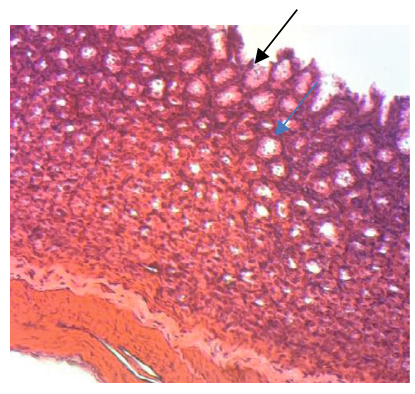

(c)

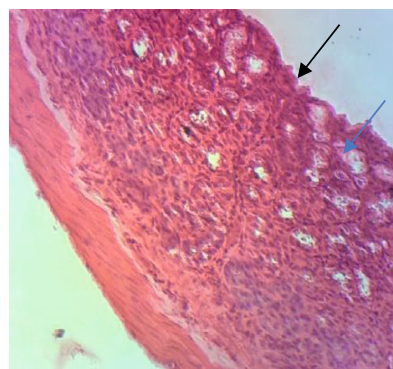

(b)

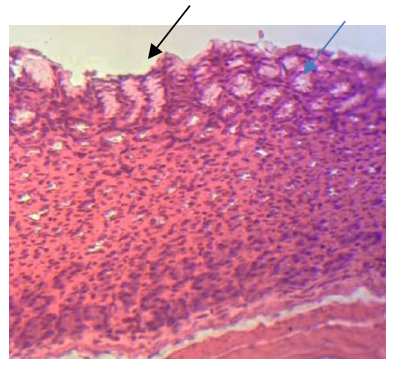

(d)

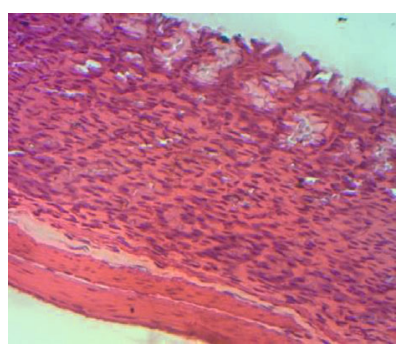

(e)

FIGURE 3: Histological study of ethanol-induced gastric damage in rats (H\&E: $\times 400)$ : (a) normal control rat: no injuries in the gastric mucosa are seen; (b) control 1 and (c) control 2: there is destruction of epithelium surface and edema; (d) sucralfate $100 \mathrm{mg} / \mathrm{kg}$ : the gastric wall appears with small destruction of epithelium and edema; (e) extract $500 \mathrm{mg} / \mathrm{kg}$ ): there is complete cicatrization of ulcerated portion.

One of the most important causes of the establishment and development of gastric ulcer in humans is ethanol, which is why gastric ulcer caused by the administration of ethanol in rats is a model essential for the preclinical study of new potentially antiulcer substances [31]. After administration of ethanol in rats, there are significant necrotic lesions and cell infiltration with significant reduction of defense factors (production of mucus, bicarbonate, and circulation of the mucous membranes) of the stomach wall [32-34]. However, it is known that one of the important elements in the 
protection of the stomach wall against multiple gastric lesions is the secretion of mucus [35]. In the present study, the methanolic extract of $D$. benthamianus significantly increased the secretion of mucus from the gastric wall, reduced the index of ulceration, and on histopathological sections confirmed the results by showing a normal mucous layer with a complete absence of gastric lesions in the treated groups compared to the untreated group. Furthermore, ethanol affects the gastric mucosa by destroying its barrier and causing microvascular changes; this leads to linear hemorrhagic lesions, mucosal friability, extensive submucosal edema, loss of epithelial cells in the stomach, and infiltration of inflammatory cells $[36,37]$. These gastric lesions due to ethanol are thought to be the consequence of a direct or indirect action of ethanol on mediators such as cytokines, COX, 5-LOX, and free oxygen radicals [38]. In fact, after administration of ethanol, an inflammatory reaction sets in and is characterized by an increase in the proinflammatory cytokines (TNF- $\alpha$, IL-1 $\beta$, and IFN $\gamma$ ), the latter will stimulate significant cellular infiltration (neutrophils and macrophages), and then, TNF- $\alpha$ will restrict gastric microcirculation and thus delay healing [39-44]. In addition, it is known that the transcription factor NF- $\kappa \mathrm{B}$, having the subunit NF- $\kappa$ B-p 65 as activation marker, plays an important role in gastric ulcer induced by ethanol as well as in the expression of various proinflammatory cytokines [40, 45]. Several authors have shown that ingestion of ethanol leads to an increase in oxidative stress and/or inflammatory cytokines which will phosphorylate the inhibitor $(\mathrm{I} \kappa \mathrm{B})$ of factor $\mathrm{NF}-\kappa \mathrm{B}$ and increase the protein expression of NF- $\kappa \mathrm{B}$ p 65 [44]. Our work has shown that the methanolic extract of $D$. benthamianus significantly inhibits the concentrations of TNF- $\alpha$, IL- $1 \beta$, IL-6, and PGE2. Thus, it is possible that the compounds present in this plant reduce the expression of the NF- $\kappa \mathrm{B}$ p65 subunit, reduce the phosphorylation of factor $\mathrm{I} \kappa \mathrm{B}$, and thus inhibit the activation of factor $\mathrm{NF}-\kappa \mathrm{B}$, leading to a significant decrease in the levels of TNF- $\alpha$ and IL- $1 \beta$. This could be justified by the presence in this plant of terpenoids because several metabolites of this class exert their anti-inflammatory effect by inhibiting the phosphorylation of the factor NF- $\kappa \mathrm{B}[46,47]$; in addition, certain phenolic compounds such as gallic acid have shown their ability to interfere with various intracellular inflammatory pathways; in fact, it inhibits the expression of nuclear transcription factor $\mathrm{NF}-\kappa \mathrm{B}$ and of the signal transducer, then regulates downwards their inflammatory targets [48].

In the model of induction of gastric lesions by NSAIDs such as indomethacin, the overproduction of proinflammatory cytokines (TNF- $\alpha, \mathrm{IL}-1 \beta$, and IL-8) is considered to be an important inducer of these lesions [49]. NSAIDs cause the activation of the cell causing the phosphorylation of factor $\mathrm{I} \kappa \mathrm{B}$ which is degraded followed by the release of NF$\kappa \mathrm{B}$, which is introduced into the nucleus of the cell and causes the transcription of numerous proinflammatory mediators including iNOS, COX-2, TNF- $\alpha$, IL- $1 \beta$, IL-6, and IL-8 [50]; thus, the aggravation of the inflammatory process in the pathophysiology of gastric ulcers would be due to an overproduction of cytokines and inflammatory mediators. Indeed, IL- $1 \beta$, IL-8, and PGE2 just like TNF- $\alpha$ promote the inflammatory response and are strongly involved in the development and maintenance of gastric ulcers in humans [51-53]. Likewise, several authors have shown that in addition to cytokines capable of stimulating the production of free radicals and disturbing the microcirculation, the activation and/or the accumulation of neutrophils are also an important factor in lesions of the gastric wall due to NSAIDs [54]. Furthermore, according to the work of Anthony et al. [55], 15 to $30 \mathrm{~min}$ after administration of indomethacin in rats, there is a significant infiltration of neutrophils into the injured mucosa. Cellular infiltration is thus considered to be a crucial step in the development of lesions of the stomach wall caused by NSAIDs. The results of this study showed that the methanolic extract of $D$. benthamianus inhibits not only the production of proinflammatory cytokines (TNF- $\alpha$, IL- $1 \beta$, and IL-6) and the production of PGE2 but also cell proliferation. It is therefore possible that the secondary metabolites present in this plant exhibited a healing effect on gastric lesions through an anti-inflammatory action, by inhibiting the activities of COX and 5-LOX and by reducing the TNF- $\alpha$, IL$1 \beta$, IL-6, and PGE2 secretions, thus leading to a reduction in mucosal cell proliferation with the consequence of stopping tissue destruction and reestablishing ulcers.

In rats, the administration of ethanol/indomethacin probably results in a significant contraction of the circular muscles of the fundic band, causing compression of the mucosa at the crests of the mucous folds, resulting in significant necrosis and ulceration as shown with ethanol by Mahmood et al. [56]. A molecule capable of causing the relaxation of these circular muscles can effectively protect the mucous membrane of the gastric wall by causing the flattening of the folds, which will have the advantage of increasing the areas of the mucous membrane exposed to necrotizing substances and thus reducing the quantity of these necrotizing substances on the crest of the stomach $[57,58]$. This study showed on micrographs of flattening of the mucous folds, suggesting that the methanolic extract of $D$. benthamianus could exert its healing effect by a significant decrease in gastric motility. Because from the experimental point of view, Abdulla et al. [57] have shown that a decrease in gastric motility is an important element in the treatment of lesions of the gastric wall [59]. This is justified by the fact that Yousseu et al. [5] showed that the methanolic extract of $D$. benthamianus significantly reduced intestinal motility in rats; this activity is linked to the presence in this extract of gallic acid which exerts its effect by blocking calcium-dependent voltage channels and/or by inhibition of muscarinic receptors [6].

In the pathogenicity of inflammatory diseases, ROS are considered amplifiers of inflammatory proliferation; they play a key role insofar as their increase leads to an amplification of inflammation, activates or suppresses the transcription factor $\mathrm{NF}-\kappa \mathrm{B}$, induces the production of numerous cytokines, and activates enzymes such as COX and 5-LOX or even inducible nitrogen monoxide [60]. In many models of gastric lesions, tissue destruction dependent on the inflammatory process is the consequence of excessive recruitment and activation of neutrophils which will be responsible for the overproduction of free radicals [61]. Many cellular damage to our organism is the cause of ROS and free radicals 
which are generally produced continuously in our body; thus, the extracellular and/or intracellular antioxidants must continually protect the tissues against oxidative damage [62]. The gastric wall damage induced by ethanol/indomethacin is linked to an exaggerated breakdown of purine which leads to an overproduction of $\mathrm{O}_{2}{ }^{-}$radicals and to an increase in lipid peroxidation mediated by ROS [63]. Lipid peroxidation is a very important pathophysiological event in various diseases, including gastric ulcer [64], because many mutagenic lesions are induced by the reaction between the MDA of lipid peroxidation and the bases of DNA [52]. Furthermore, it is known that in rats, the administration of antioxidants significantly reduces the gastric damage caused by ethanol and/or indomethacin [65]. The methanolic extract of D. benthamianus has shown significant antioxidant activity by reducing the level of MDA and increasing the activities of catalase, GSH, and SOD. Furthermore, this extract significantly inhibits the production of extracellular and intracellular ROS in whole blood and in various phagocytic cells (neutrophils and macrophages). This activity would be due to the inhibition of the production of proinflammatory cytokines (TNF- $\alpha$, IL- $1 \beta$, and IL-6), to the inhibition of protein denaturation, and to the inhibition of proinflammatory enzymatic activity, such as COX and 5-LOX. This can be justified by the fact that the gallic acid contained in the extract reduces the expression and/or activity of the proinflammatory cytokines and inflammatory proteins, including TNF- $\alpha$, interferon- $\gamma$ (INF- $\gamma$ ), IL-1 $\beta$, IL-6, IL-17, IL-21, IL-23, cyclooxygenase (COX), and iNOS, and decreases expression and liberation of neutrophils and macrophages [48]. In addition, gallic acid improves the hepatotoxic effects of xenobiotic agents by acting as an antioxidant compound that eliminates free radicals, such as ROS, and improves the capacity of antioxidant defense systems [66].

Histological analysis of the stomach of the rats revealed the presence of lesions in the mucosa as well as edema in controls 1 and 2. This result shows an implication of the inflammatory process which took place in these controls. The normalization of the tissue in the rat treated with the methanolic extract of $D$. benthamianus causes reepithelialization of the mucosa, which shows that the extract would accelerate the healing of the ulcer and promote the regeneration of the gastric mucosa. The destruction of tissues and/or organs is very often the consequence of an unmodulated inflammatory response [67]. When there is a tissue disorder in the epithelium, a tissue repair program is immediately launched. The stomach crypts are an important reservoir of stem cells which first differentiate into progenitor cells and eventually become lineages of epithelial cells in order to activate the process. Thus, several previous studies have explained the role of TNF- $\alpha$ and IL- $1 \beta$ as indirect mediators of an endogenous tissue regeneration signal [68]. The layer of epithelial cells represents the second line of defense of the mucosa. This epithelial tissue is responsible for the production of mucus, bicarbonate, and other components of the mucobicarbonate barrier [69]. This result is in agreement with those obtained by Ateufack et al. [70] who have shown that the aqueous and methanolic extracts of $D$. benthamianus regenerate the gastric epithelium of rats subjected to acetic acid. In addition, the regenerative power of the extract has also been proven on the epithelium of two other organs, namely, the colon and the ileum by Yousseu et al. [5]. The compounds present in the extract would have activated several signaling pathways thus facilitating tissue reconstruction.

During the healing process of gastric ulcers, which is very complex and has several sequential phases (hemostasis, inflammation, proliferation, and remodeling), the tissues separate after the injury to restore the integrity of the mucosa [71]. It is known that controlling the production of stomach acid remains an important element in the healing of ulcers; however, the complex ulcer repair mechanisms show that the quality and speed of healing can be pharmacologically modulated. One of the main options being explored today is the use of dual COX and 5-LOX inhibitors which are able to prevent gastric mucosal ulcers from the exaggerated production of leukotrienes [72]. This is the case of licofelone which is a double inhibitor of COX and 5-LOX which can be administered for 4 to 12 weeks without altering the gastric mucosa in humans $[73,74]$. Thus, with its antisecretory and cytoprotective properties, double inhibitor of COX/5-LOX, antioxidant properties, and inhibitors of the secretion of proinflammatory cytokines, the methanolic extract of $D$. benthamianus remains a good candidate for further studies in research of drugs which can bring about a complete cure of gastric ulcerations.

\section{Conclusion}

In conclusion, in vitro studies have shown that the methanolic extract of $D$. benthamianus has healing properties against gastric ulcers caused by ethanol and/or indomethacin. This effect would be linked to the inhibitory properties of the extract on protein denaturation; the activities of 5-LOX and COX; the production of ROS, proinflammatory cytokines, PGE2; and a decrease in the proliferation of lymphocytes. This effect can also be associated with the antioxidant properties and the ability to reepithelialize the plant. Thus, the presence of compounds such as gallic acid and other phenolic compounds may be partially responsible for these activities.

\section{Data Availability}

All data supporting our findings are adequately contained within the manuscript.

\section{Ethical Approval}

The experimental procedures have been approved by the local ethics committee and are in accordance with the guidelines for the study of pain in awake animals, published by the NIH (publication no. 85-23), "Principles of Animal Protection," Laboratory, Study of Pain, Ministry of Scientific Research and Technology, which adopted the European Union Guidelines on Animal Care and Experimentation (EWC 86/609). For the donation of human blood samples, all processes of collecting blood are accepted by the Independent Ethics Committee, ICCBS, University of Karachi, No. ICCBS/IEC-008-BC-2015/Protocol/1.0. The blood donors 
were provided informed approval for the use of their blood for the purposes of this study.

\section{Conflicts of Interest}

$\mathrm{MM}(\mathrm{PhD})$ is a senior lecturer in the Department of Animal Biology, Faculty of Science, University of Dschang, Cameroon. AAD ( $\mathrm{PhD})$ is a senior lecturer in the Department of Animal Biology, Faculty of Science, University of Yaounde 1, Cameroon. DNSF, TEG, MMMV, MKYK, and NAE are PhD students in the Department of Animal Biology, Faculty of Science, University of Dschang, Cameroon. AG is an associate professor in the Department of Animal Biology, Faculty of Science, University of Dschang, Cameroon. The authors declare that they have no conflicts of interest.

\section{Authors' Contributions}

MMVM, AG, and MM designed the work. MMVM, AG, MM, AAD, ACF, DNSF, TEG, YNW, MKYK, and NAE conducted the work and collected and analysed the data. MMVM, AG, MM, YNW, and AAD drafted the manuscript and revised it critically. All authors agree to be accountable for all aspects of the work.

\section{Acknowledgments}

The authors would like to thank the study participants; the staff of Department of Pharmaceutical Sciences, COMSATS Institute of Information Technology, Abbottabad 22060, Pakistan; and ICCBS (International Center for Chemical and Biological Sciences), University of Karachi, for the realization of the in vitro part of this work.

\section{References}

[1] E. P. Berry, D. Isely, and B. L. Turner, "Fabales, Encyclopædia Britannica," 2018, https://www.britannica.com/plant/Fabales.

[2] F. E. Dickinson, R. W. Hess, and F. F. Wangaard, "Properties and uses of tropical woods," Tropical Woods, vol. 95, p. 145, 1945.

[3] E. M. P. Nguelefack, K. B. Ngu, A. Atchade, T. Dimo, N. Tsabang, and T. Mbafor, "Phytochemical composition and in vitro effects of the ethyl acetate bark extract of Distemonanthus benthamianus Baillon (Caesalpiniaceae) on Staphylococcus aureus and Streptococcus agalactiae," Cameroon Journal of Experimental Biology, vol. 1, no. 1, pp. 50-53, 2006.

[4] K. C. Ndukwe, I. N. Okeke, A. Lamikanra, S. K. Adesina, and O. Aboderin, "Antibacterial activity of aqueous extracts of selected chewing sticks," Journal of Contemporary Dental Practice, vol. 6, no. 3, pp. 86-94, 2005.

[5] N. Yousseu, G. Ateufack, J. Abdul et al., "Extracts from the trunk bark of Distemonanthus benthamianus Baillon. (Caesalpiniaceae) developed antidiarrhoeal activities in rats and mice," Oriental Pharmacy and Experimental Medicine, vol. 19, pp. 421-433, 2019.

[6] W. Yousseu Nana, G. Ateufack, M. Mbiantcha et al., "Antidiarrheal potential of Distemonanthus benthamianus Baillon. extracts via inhibiting voltage-dependent calcium channels and cholinergic receptors," Asian Pacific Journal of Tropical Biomedicine, vol. 9, no. 11, pp. 449-455, 2019.
[7] Y. N. William, A. Gilbert, A. J. Shah et al., "Curative effects of Distemonanthus benthamianus Baillon. Trunk-bark extracts on enteropathogenic Escherichia coli 31-induced diarrhea in rats," Journal of Complementary and Alternative Medicine, vol. 16, no. 4, 2019.

[8] D. A. O. Valim Araujo, C. Takayama, F. M. de Faria et al., "Gastroprotective effects of essential oil from Protium heptaphyllum on experimental gastric ulcer models in rats," Brazilian Journal of Pharmacognosy, vol. 21, no. 4, pp. 721-729, 2011.

[9] H. E. Vonkeman, R. M. Klok, M. J. Postma, J. R. Brouwers, and M. A. F. J. van de Laar, "Direct medical costs of serious gastrointestinal ulcers among users of NSAIDs," Drugs \& Aging, vol. 24, no. 8, pp. 681-690, 2007.

[10] M. M. Wolfe, D. R. Lichtenstein, and G. Singh, "Gastrointestinal toxicity of nonsteroidal antiinflammatory drugs," The New England Journal of Medicin, vol. 340, no. 24, pp. 1888-1899, 1999.

[11] A. Franke, S. Teyssen, and M. V. Singer, "Alcohol-related diseases of the esophagus and stomach," Digestive Diseases, vol. 23, pp. 204-213, 2006.

[12] D. Laloo, S. K. Prasad, S. Krishnamurthy, and S. Hemalatha, "Gastroprotective activity of ethanolic root extract of Potentilla fulgens Wall. ex Hook," Journal of Ethnopharmacology, vol. 146, no. 2, pp. 505-514, 2013.

[13] P. Antonisamy, P. Subash-Babu, A. A. Alshatwi et al., "Gastroprotective effect of nymphayol isolated from Nymphaea stellata (Willd.) flowers: contribution of antioxidant, antiinflammatory and antiapoptotic activities," Chemico-Biological Interactions, vol. 224, pp. 157-163, 2014.

[14] T. Yoshikawa, Y. Naito, A. Kishi et al., "Role of active oxygen, lipid peroxidation, and antioxidants in the pathogenesis of gastric mucosal injury induced by indomethacin in rats," Gut, vol. 34, no. 6, pp. 732-737, 1993.

[15] S. F. Djuichou Nguemnang, E. G. Tsafack, M. Mbiantcha et al., "In vitro anti-inflammatory and in vivo antiarthritic activities of aqueous and ethanolic extracts of Dissotis thollonii Cogn. (Melastomataceae) in rats," Evidence-based Complementary and Alternative Medicine, vol. 2019, Article ID 3612481, 17 pages, 2019.

[16] G. Elias and M. N. Rao, "Inhibition of albumin denaturation and anti-inflammatory activity of dehydrozingerone and its analogs," International Journal of Experimental Pathology, vol. 10, pp. 540-542, 1988.

[17] V. Viji and A. Helen, "Inhibition of lipoxygenases and cyclooxygenase-2 enzymes by extracts isolated from Bacopa monniera (L.) Wettst," Journal of Ethnopharmacology, vol. 118, no. 2, pp. 305-311, 2008.

[18] M. Zimmerman, "Ethical guidelines for investigations of experimental pain in conscious animals," Pain, vol. 16, no. 2, pp. 109-110, 1983.

[19] M. A. Mesaik, Zaheer-Ul-Haq, S. Murad et al., "Biological and molecular docking studies on coagulin-H: human IL-2 novel natural inhibitor," Molecular Immunology, vol. 43, no. 11, pp. 1855-1863, 2006.

[20] M. F. Mahomoodally, A. Gurib-Fakim, and A. H. Subratty, "Effect of exogenous ATP on Momordica charantia Linn. (Cucurbitaceae) induced inhibition of D-glucose, L-tyrosine and fluid transport across rat everted intestinal sacs in vitro," Journal of Ethnopharmacology, vol. 110, no. 2, pp. 257-263, 2007. 
[21] R. Vinegar, W. Schreiber, and R. Hugo, "Biphasic development of carrageenin edema in rats," Journal of Pharmacology and Experimental Therapeutics, vol. 166, no. 1, pp. 96-103, 1969.

[22] A. Azadmehr, G. Maliji, R. Hajiaghaee, M. Shahnazi, and A. Afaghi, "Inhibition of pro-inflammatory cytokines by ethyl acetate extract of Scrophularia striata," Tropical Journal of Pharmaceutical Research, vol. 11, no. 6, pp. 893-897, 2012.

[23] L. Philippe, P. Gegout-Pottie, C. Guingamp et al., "Relations between functional, inflammatory, and degenerative parameters during adjuvant arthritis in rats," American Journal of Physiology-Regulatory Integrative and Comparative Physiology, vol. 273, no. 4, pp. R1550-R1556, 1997.

[24] F. Salie, P. Eagles, and H. Leng, "Preliminary antimicrobial screening of four South African Asteraceae species," Journal of Ethnopharmacology, vol. 52, no. 1, pp. 27-33, 1996.

[25] J. Wang, S. Yamasaki, K. Takeuchi, and S. Okabe, "Delayed healing of acetic acid-induced gastric ulcers in rats by indomethacin," Gastroenterology, vol. 96, no. 2, pp. 393-402, 1989.

[26] B. Adinortey, A. Charles, G. Isaac, and N. Alexander, "In vivo models used for evaluation of potential antigastroduodenal ulcer agents," Ulcers, vol. 2013, Article ID 796405, 12 pages, 2013.

[27] G. L. Ellman, "Tissue sulfhydryl groups," Archives of Biochemistry and Biophysics, vol. 82, no. 1, pp. 70-77, 1959.

[28] H. P. Misra and I. Fridovich, "The role of superoxide anion in the autoxidation of epinephrine and a simple assay for superoxide dismutase," Journal of Biological Chemistry, vol. 247, no. 10, pp. 3170-3175, 1972.

[29] A. K. Sinha, "Colorimetric assay of catalase," Annual Review of Biochemistry, vol. 47, no. 2, pp. 389-394, 1972.

[30] K. M. Wilbur, F. Bernheim, and O. W. Shapiro, "Determination of lipid peroxidation," Archives of Biochemistry and Biophysics, vol. 24, pp. 305-310, 1949.

[31] H. H. Arab, S. A. Salama, H. A. Omar, E. S. A. Arafa, and I. A. Maghrabi, "Diosmin protects against ethanol-induced gastric injury in rats: novel anti-ulcer actions," PLoS One, vol. 10, no. 3, article e0122417, 2015.

[32] E. Marhuenda, M. J. Martin, and C. D. L. Alarcon Lastra, "Antiulcerogenic activity of aescine in different experimental models," Phytotherapy Research, vol. 7, no. 1, pp. 13-16, 1993.

[33] M. D. P. Ferreira, C. M. Nishijima, L. N. Seito et al., "Gastroprotective effect of Cissus sicyoides (Vitaceae): involvement of microcirculation, endogenous sulfhydryls and nitric oxide," Journal of Ethnopharmacology, vol. 117, no. 1, pp. 170-174, 2008.

[34] N. Sistani Karampour, A. Arzi, A. Rezaie, M. Pashmforoosh, and F. Kordi, "Gastroprotective effect of zingerone on ethanol-induced gastric ulcers in rats," Medicina, vol. 55, no. 3, p. 64, 2019.

[35] F. S. Oluwole, J. A. Ayo, B. O. Omolaso, B. O. Emikpe, and J. K. Adesanwo, "Methanolic extract of Tetracera potatoria, an antiulcer agent increases gastric mucus secretion and endogenous antioxidants," Nigerian Journal of Physiological Sciences, vol. 23, no. 1-2, pp. 79-83, 2008.

[36] F. C. Moleiro, M. A. Andreo, R. D. C. D. Santos et al., "Mouriri elliptica: validation of gastroprotective, healing and anti-Helicobacter pylori effects," Journal of Ethnopharmacology, vol. 123, no. 3, pp. 359-368, 2009.

[37] W. Jelski, M. Kozlowski, J. Laudanski, J. Niklinski, and M. Szmitkowski, "The activity of class I, II, III, and IV alcohol dehydrogenase $(\mathrm{ADH})$ isoenzymes and aldehyde dehydroge- nase (ALDH) in esophageal cancer," Digestive Diseases and Sciences, vol. 54, no. 4, pp. 725-730, 2009.

[38] O. M. E. Abdel-Salam, J. Czimmer, A. Debreceni, J. Szolcsányi, and G. Mózsik, "Gastric mucosal integrity: gastric mucosal blood flow and microcirculation. An overview," Journal of Physiology Paris, vol. 95, no. 1-6, pp. 105-127, 2001.

[39] X. Mei, D. Xu, S. Xu, Y. Zheng, and S. Xu, "Novel role of $\mathrm{Zn}$ (II)-curcumin in enhancing cell proliferation and adjusting proinflammatory cytokine-mediated oxidative damage of ethanol-induced acute gastric ulcers," Chemico-Biological Interactions, vol. 197, no. 1, pp. 31-39, 2012.

[40] S. Verma and V. L. Kumar, "Attenuation of gastric mucosal damage by artesunate in rat: modulation of oxidative stress and $\mathrm{NF} \kappa \mathrm{B}$ mediated signaling," Chemico-Biological Interactions, vol. 257, pp. 46-53, 2016.

[41] S. Wang, Y. Ni, J. Liu et al., "Protective effects of Weilikang decoction on gastric ulcers and possible mechanisms," Journal of Natural Medicines, vol. 70, no. 3, pp. 391-403, 2016.

[42] M. A. Vinolo, H. G. Rodrigues, E. Hatanaka, C. B. Hebeda, S. H. Farsky, and R. Curi, "Short-chain fatty acids stimulate the migration of neutrophils to inflammatory sites," Clinical Science, vol. 117, no. 9, pp. 331-338, 2009.

[43] R. Hasgul, S. Uysal, H. Haltas et al., "Protective effects of Ankaferd blood stopper on aspirin-induced oxidative mucosal damage in a rat model of gastric injury," Toxicology and Industrial Health, vol. 30, pp. 888-895, 2012.

[44] T. Lawrence, "The nuclear factor NF- $\kappa$ B pathway in inflammation," Cold Spring Harbor Perspectives in Biology, vol. 1, article a001651, 2009.

[45] H. S. El-Abhar, "Coenzyme Q10: a novel gastroprotective effect via modulation of vascular permeability, prostaglandin $\mathrm{E}_{2}$, nitric oxide and redox status in indomethacin-induced gastric ulcer model," European Journal of Pharmacology, vol. 649, no. 1-3, pp. 314-319, 2010.

[46] T. Rabi, S. Shukla, and S. Gupta, "Betulinic acid suppresses constitutive and TNF $\alpha$-induced NF- $\kappa \mathrm{B}$ activation and induces apoptosis in human prostate carcinoma PC-3 cells," Molecular Carcinogenesis, vol. 47, no. 12, pp. 964-973, 2008.

[47] H. Yu-Jin, S. Jaewhan, K. Haeng-Ran, and A. H. Kyung, "Oleanolic acid regulates NF- $\kappa \mathrm{B}$ signaling by suppressing MafK expression in RAW 264.7 cells," BMB Reports, vol. 47, no. 9, pp. 524-529, 2014.

[48] A. Pandurangan, N. Mohebali, M. Norhaizan, and C. Looi, "Gallic acid attenuates dextran sulfate sodium-induced experimental colitis in BALB/c mice," Drug Design, Development and Therapy, vol. 9, pp. 3923-3934, 2015.

[49] T. Kyoi, S. Kitazawa, K. Tajima, X. Zhang, and Y. Ukai, "Phosphodiesterase type IV inhibitors prevent ischemiareperfusion-induced gastric injury in rats," Journal of Pharmacological Sciences, vol. 95, no. 3, pp. 321-328, 2004.

[50] S. Guan, Y. Zheng, X. Yu, W. Li, B. Han, and J. Lu, "Ellagic acid protects against LPS-induced acute lung injury through inhibition of nuclear factor kappa B, proinflammatory cytokines and enhancement of interleukin-10," Food and Agricultural Immunology, vol. 28, no. 6, pp. 1347-1361, 2017.

[51] T. Watanabe, K. Higuchi, M. Hamaguchi et al., "Monocyte chemotactic protein-1 regulates leukocyte recruitment during gastric ulcer recurrence induced by tumor necrosis factor- $\alpha$," American Journal of Physiology-Gastrointestinal and Liver Physiology, vol. 287, no. 4, pp. G919-G928, 2004. 
[52] A. Hamlet, C. Lindholm, O. Nilsson, and L. Olbe, "Aspirininduced gastritis, like Helicobacter pylori-induced gastritis disinhibits acid secretion in humans: relation to cytokine expression," Scandinavian Journal of Gastroenterology, vol. 33, no. 4, pp. 346-356, 1998.

[53] M. Odashima, M. Otaka, M. Jin et al., "Attenuation of gastric mucosal inflammation induced by aspirin through activation of $\mathrm{A}_{2 \mathrm{~A}}$ adenosine receptor in rats," World Journal of Gastroenterology, vol. 12, no. 4, pp. 568-573, 2006.

[54] J. L. Wallace, "Nonsteroidal anti-inflammatory drugs and gastroenteropathy: the second hundred years," Gastroenterology, vol. 112, no. 3, pp. 1000-1016, 1997.

[55] A. Anthony, R. Sim, A. P. Dhillon, R. E. Pounder, and A. J. Wakefield, "Gastric mucosal contraction and vascular injury induced by indomethacin precede neutrophil infiltration in the rat," Gut, vol. 39, no. 3, pp. 363-368, 1996.

[56] A. A. Mahmood, F. H. Al-Bayaty, I. Salmah, N. Syuhada, H. Harita, and F. Mughrabi, "Enhancement of gastric ulcer by Areca catechu nut in ethanol-induced gastric mucosal injuries in rats," Journal of Medicinal Plant Research, vol. 5, no. 12, pp. 2562-2569, 2011.

[57] M. A. Abdulla, K. A. A. Ahmed, F. H. Al-Bayaty, and Y. Masood, "Gastroprotective effect of Phyllanthus niruri leaf extract against ethanol-induced gastricmucosal injury in rats," African Journal of Pharmacy and Pharmacology, vol. 4, no. 5, pp. 226-230, 2010.

[58] S. Q. Wasman, A. A. Mahmood, H. Salehhuddin, A. A. Zahra, and I. Salmah, "Cytoprotective activities of Polygonum minus aqueous leaf extract on ethanol-induced gastric ulcer in rats," Journal of Medicinal Plant Research, vol. 4, no. 24, pp. 26582665, 2010.

[59] A. S. AlRashdi, S. M. Salama, S. S. Alkiyumi et al., "Mechanisms of gastroprotective effects of ethanolic leaf extract of Jasminum sambac against $\mathrm{HCl} /$ ethanol-induced gastric mucosal injury in rats," Evidence-based Complementary and Alternative Medicine, vol. 2012, 15 pages, 2012.

[60] A. Jabeen, M. A. Mesaik, S. U. Simjee, S. B. Lubna, S. Bano, and S. Faizi, "Anti-TNF- $\alpha$ and anti-arthritic effect of patuletin: a rare flavonoid from Tagetes patula," International Immunopharmacology, vol. 36, pp. 232-240, 2016.

[61] F. B. Potrich, A. Allemand, L. M. da Silva et al., "Antiulcerogenic activity of hydroalcoholic extract of Achillea millefolium L.: involvement of the antioxidant system," Journal of Ethnopharmacology, vol. 130, no. 1, pp. 85-92, 2010.

[62] B. Halliwell, K. Zhao, and M. Whiteman, "The gastrointestinal tract: a major site of antioxidant action?," Free Radical Research, vol. 33, no. 6, pp. 819-830, 2015.

[63] A. Bhattacharyya, R. Chattopadhyay, S. Mitra, and S. E. Crowe, "Oxidative stress: an essential factor in the pathogenesis of gastrointestinal mucosal diseases," Physiological Reviews, vol. 94, no. 2, pp. 329-354, 2014.

[64] D. Bandyopadhyay, K. Biswas, M. Bhattacharyya, R. Reiter, and R. Banerjee, "Gastric toxicity and mucosal ulceration induced by oxygen-derived reactive species: protection by melatonin," Current Molecular Medicine, vol. 1, no. 4, pp. 501513, 2001.

[65] R. Sathish, A. Sahu, and K. Natarajan, "Antiulcer and antioxidant activity of ethanolic extract of Passiflora foetida L," Indian Journal of Pharmacology, vol. 43, no. 3, pp. 336-339, 2011.
[66] G. Bayramoglu, H. Kurt, A. Bayramoglu, H. Gunes, I. Degirmenci, and S. Colak, "Preventive role of gallic acid on hepatic ischemia and reperfusion injury in rats," Cytotechnology, vol. 67, no. 5, pp. 845-849, 2015.

[67] F. Peñaloza, M. Schultz, P. Nieto et al., "Opposing roles of IL10 in acute bacterial infection," Cytokine Growth Factor Reviue, vol. 32, pp. 17-30, 2016.

[68] R. Abarca-Buis, A. Martínez-Jiménez, E. Vera-Gómez et al., "Mechanisms of epithelial thickening due to IL-1 signalling blockade and TNF- $\alpha$ administration differ during wound repair and regeneration," Differentiation, vol. 99, pp. 10-20, 2018.

[69] C. Valérie and S. Tina, Essentials of Anatomy and Physiology, 366-380, 2007.

[70] G. Ateufack, M. Matah, H. Tchoumbou et al., "Preventive and curative properties of aqueous and methanolic extracts of Distemonanthus benthamianus stem barks on acute and chronic gastric ulcers in male rats," European Journal of Pharmaceutical and Medical Research, vol. 5, pp. 402-413, 2018.

[71] W. K. Stadelmann, A. G. Digenis, and G. R. Tobin, "Physiology and healing dynamics of chronic cutaneous wounds," American Journal of Surgery, vol. 176, no. 2, pp. 26S-38S, 1998.

[72] C. Blandizzi, M. Tuccori, R. Colucci et al., "Role of coxibs in the strategies for gastrointestinal protection in patients requiring chronic non-steroidal anti-inflammatory therapy," Pharmacological Research, vol. 59, no. 2, pp. 90-100, 2009.

[73] P. Bias, A. Buchner, B. Klesser, and S. Laufer, “The gastrointestinal tolerability of the LOX/COX inhibitor, licofelone, is similar to placebo and superior to naproxen therapy in healthy volunteers: results from a randomized, controlled trial," American Journal of Gastroenterology, vol. 99, no. 4, pp. 611-618, 2004.

[74] J. C. Becker, W. Domschke, and T. Pohle, "Current approaches to prevent NSAID-induced gastropathy-COX selectivity and beyond," British Journal of Clinical Pharmacology, vol. 58, no. 6, pp. 587-600, 2004. 